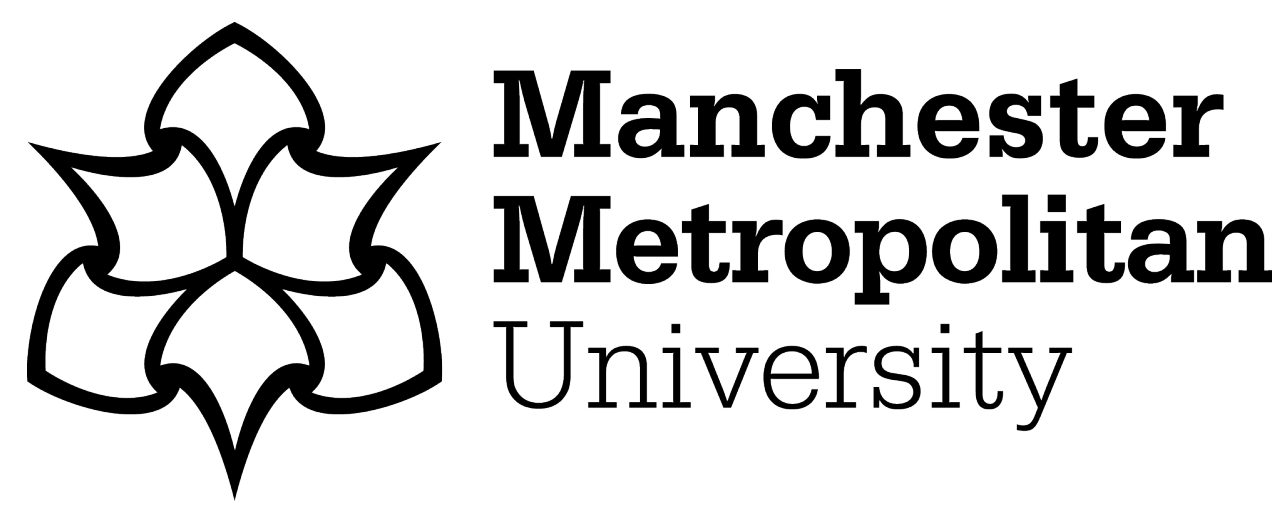

Li, Z, Haigh, A, Soutis, C, Gibson, A, Sloan, R and Karimian, N (2016) Delamination detection in composite T-joints of wind turbine blades using microwaves. Advanced Composites Letters, 25 (4). pp. 83-86.

Downloaded from: https://e-space.mmu.ac.uk/625406/

Version: Accepted Version

Publisher: Sage

DOI: https://doi.org/10.1177/096369351602500401

Please cite the published version 


\title{
DELAMINATION DETECTION IN COMPOSITE T-JOINTS OF WIND TURBINE BLADES USING MICROWAVES
}

\author{
Zhen $\mathrm{Li}^{1}$, Arthur Haigh ${ }^{2}$, Constantinos Soutis ${ }^{1,3 *}$, Andrew Gibson ${ }^{3}$, \\ Robin Sloan ${ }^{2}$ and Noushin Karimian ${ }^{3}$ \\ ${ }^{1}$ Aerospace Research Institute, ${ }^{2}$ School of Electrical and Electronic Engineering, \\ ${ }^{3}$ School of Mechanical, Aerospace and Civil Engineering \\ The University of Manchester, Manchester, M13 9PL, UK
}

*Author to whom correspondence should be addressed: constantinos.soutis@manchester.ac.uk

\begin{abstract}
The wind turbine is playing an increasingly important role in the generation of green electricity. The structural integrity and maintenance of the wind turbine blade is a critical issue in service due to the harsh operating environments. In this paper, the delamination in glass fibre composite joints of a wind turbine blade is detected using the non-contact microwave imaging with an open-ended waveguide. The existence and extent of the delaminated region could be found from the generated images. Thickness variation and the presence of the web can be identified as well. The optimum inspection frequency range is investigated, which offers a reference for future applications. By comparison, the phase profiling provided by the scanning shows better performance for the delamination detection rather than the magnitude profiling.
\end{abstract}

Keywords: wind turbine blade, $\mathrm{T}$-joints, delamination, non-destructive testing, microwaves

\section{INTRODUCTION}

In recent years, wind energy harvesting has attracted more and more attention due to the increased public awareness of impending climate change situations and the improved efficiency of wind energy systems [1-2]. A wind turbine is the primary device for the electricity generation from wind power. The wind turbine blades are usually made of glass-fibre reinforced polymer (GFRP) composites, as they provide low cost, light weight, better fatigue and corrosion resistance, high specific stiffness and strength. However, blade failure accounts for most accidents and damage to wind turbines in service, so the structural health monitoring and fault diagnosis of the blade is a critical issue in the operation and maintenance. The blades are subjected to both static and dynamic lift, gravitational loads and drag during an approximately 20-year life cycle [3]. Some typical types of blade damage are delamination, skin/adhesive debonding, sandwich debonding and buckling induced skin/adhesive debonding [4]. Specifically, the upper spar cap/flange of the spar is one of the areas that are prone to damage [5]. 
For these reasons, a number of non-destructive testing (NDT) techniques have been employed to identify damage in the composite blade [6], for example, conventional strain gauges, ultrasonic testing, vibration method, acoustic emission, thermography, optical fibre sensors, shearography, digital image correlation and X-ray imaging. It should be pointed out that there exists no method that could be utilised to detect all kinds of defects in all material types. Each NDT method has its own particular advantages and limitations. To the best knowledge of the authors, a little work has been done on the detection of damage in the wind turbine blades using the microwave techniques. For the detection of defects in glass fibre composites, the microwave techniques have been proved to be superior to some other NDT methods [7]. The microwave methods have various attributes, such as non-contact, one-sided scanning, no need for transducers or couplants and no safety hazards due to low power of the signal used [8].

In this paper, the open-ended waveguide imaging method, one of the microwave techniques, is applied for the detection of delamination in GFRP T-joints. The setup for the microwave inspection is described in detail. Discussions on the effect of the inspection frequency on the performance and the selection of the indicator for damage detection are presented.

\section{GLASS-FIBRE COMPOSITE T-JOINTS}

As illustrated in Fig. 1 (a), the T-joint in the wind turbine blade is a vital component, which provides the connection between the web and the skin. Specifically, as presented in Fig. 1 (b), the T-joint under test is made up of the web, flange, skin and stiffener [9]. The delamination between the flange and the skin is the common damage type in the field due to the relatively low interlaminar strength. It is important to introduce a NDT technique for detection and evaluation of the delamination, since it is difficult to see the damage from the outside by naked eyes.

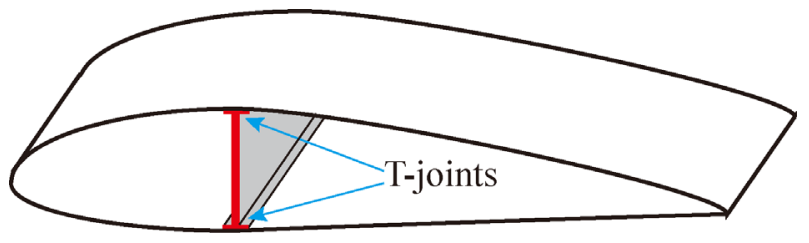

(a)

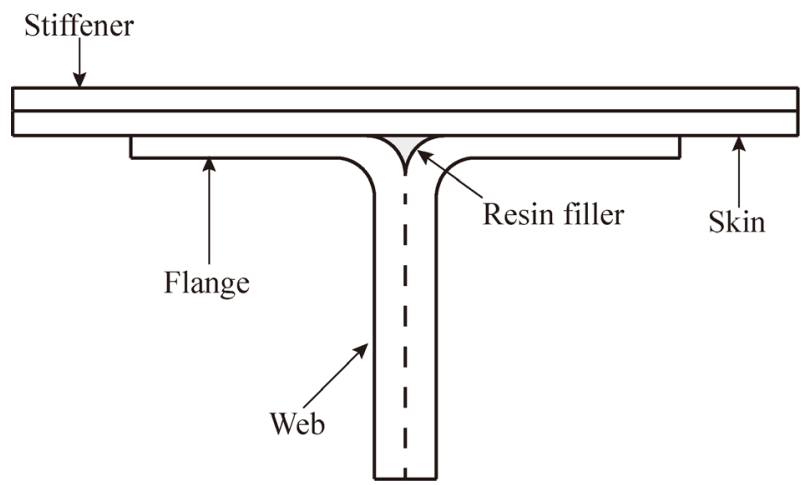

(b)

Fig.1: Schematic diagram of the GFRP composite T-joint:

(a) Cross-section of the wind turbine blade, (b) Structure of the T-joint under test Two T-joint samples under test denoted by T-joint I and II are shown in Fig. 2. The stacking sequence of the flange and skin is $\left[45^{\circ} /-45^{\circ}\right]_{5}$, and the web is a $\left[45^{\circ} /-45^{\circ}\right]_{10}$ plate. The stiffener 
consists of five-layer unidirectional $\left[0^{\circ}\right]_{5}$ to prevent large deflections. The delamination in each sample was induced by the pull-out test. Total thicknesses of the cured base (flange, skin and stiffener) of T-joint I and II are $7.66 \mathrm{~mm}$ and $8.66 \mathrm{~mm}$, respectively.

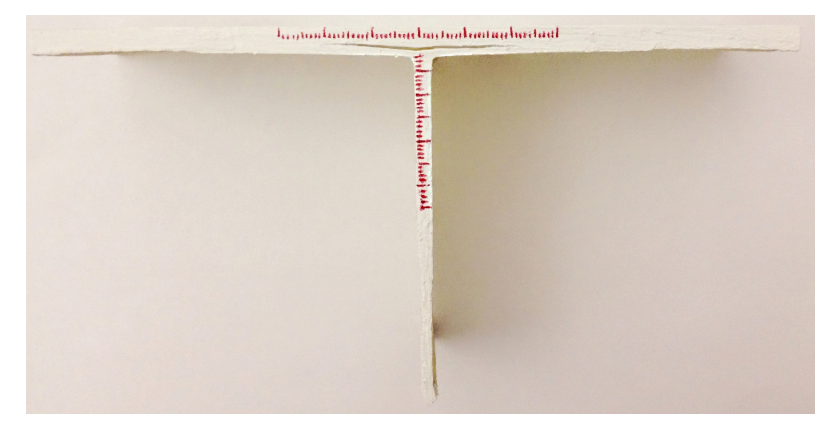

(a)

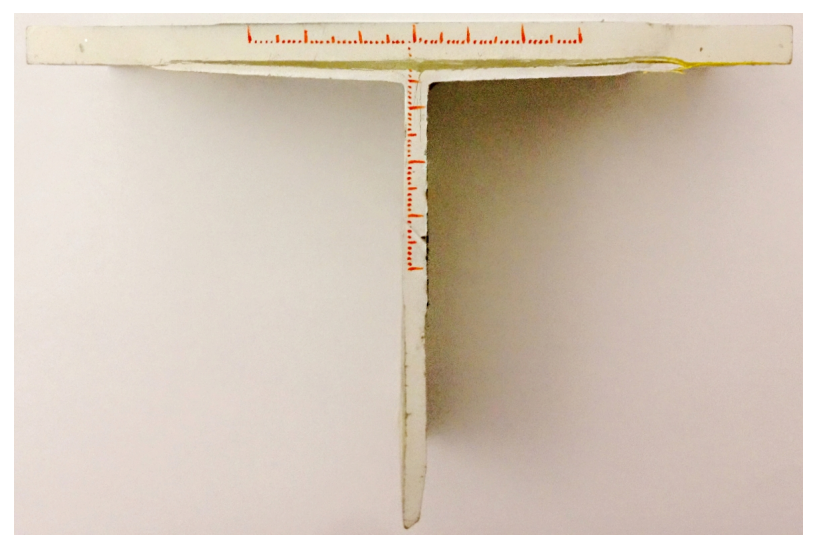

(b)

Fig.2: Photographs of two GFRP T-joint samples: (a) T-joint I, (b) T-joint II

\section{EXPERIMENTAL SETUP}

The microwave imaging with an open-ended waveguide is employed because of its easy setup, capability of non-contact inspection and no need for signal processing or significant operator expertise [10]. In the test, a $\mathrm{K}$ band (18.0-26.5 GHz) rectangular waveguide adapter is used. The dimensions of the waveguide are presented in Fig. 3 (a). The waveguide assembly is mounted on an XYZ scanning stage and connected to an HP8720D vector network analyser (VNA) (50 MHz-20 $\mathrm{GHz}$ ) by a semi-rigid coaxial cable. A personal computer (PC) is connected to the PIC18C452 Microchip ${ }^{\circledR}$ microcontroller for the logic control of the stepper motors. VEE software ${ }^{\circledR}$ is employed for precise and reproducible movements of the sensor. In addition, the analyser is connected to the PC by the IEEE-488 cable for data acquisition. The frequency range employed is $18-20 \mathrm{GHz}$.

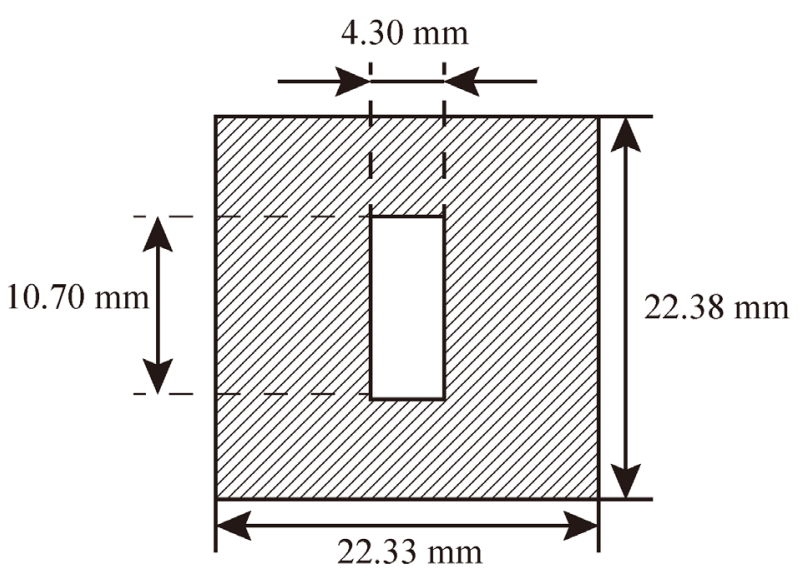

(a)

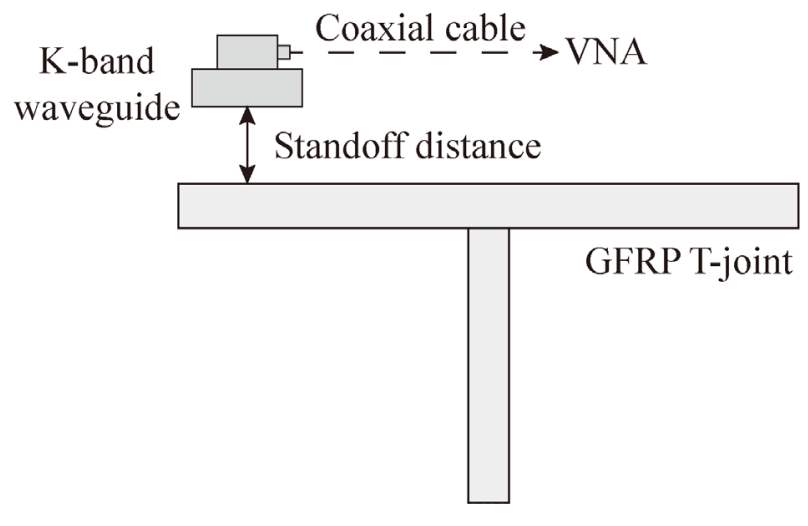

(b)

Fig.3: Experimental setup using the microwave imaging with an open-ended waveguide:

(a) size of the aperture, (b) schematic diagram of the setup 
As shown in Fig. 4, the raster (2D) scanning is performed over the skin with the effective scanning area of $141.74 \mathrm{~mm} \times 27.28 \mathrm{~mm}$. The step size used for scanning is $1 \mathrm{~mm}$ with the standoff distance of $5 \mathrm{~mm}$. T-joint I is used to thoroughly study the characteristics of the microwave imaging. It should be noted that there is a slight increase in the thickness from the edge to the central region on the top surface due to the introduction of the flange underneath, which would affect the propagation of the electromagnetic waves and the reflected energy. The distances between the centre of the waveguide at the origin and the locations of interest are demonstrated in Fig. 5.

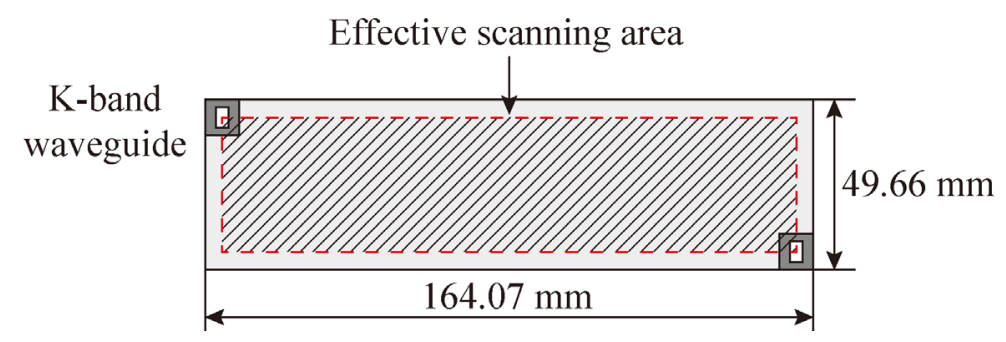

Fig.4: 2D scanning over the top surface of T-joint I

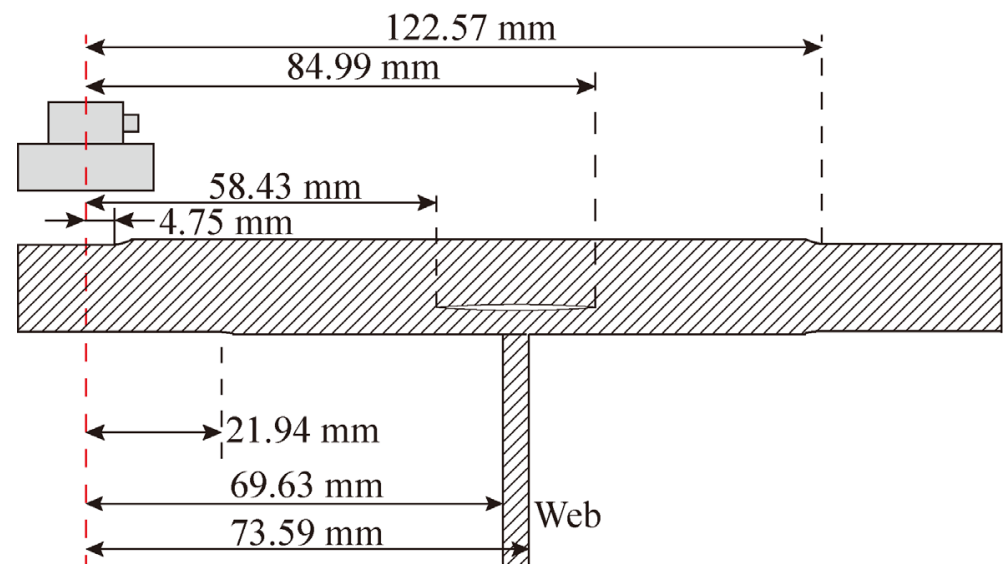

Fig.5: Detailed locations of interest in T-joint I with respect to the starting point of the waveguide

\section{EXPERIMENTAL RESULTS}

As a one-port measurement, only the reflection coefficient $\mathrm{S}_{11}$ is acquired from the analyser. It has been found that phase information is more sensitive than the magnitude [11]. Accordingly, the distribution of the phase at each sampling position is plotted. As seen in Fig. 6, at the inspection frequency of $19 \mathrm{GHz}$, both the delamination and the variation of the thickness can be detected. In addition, the presence of the web is well presented. It is shown that the size of the blue region is slightly larger than the real size of the web, which is primarily due to the transition in the thickness from the skin to the web and the intrinsic limited resolution provided by the technique that is dependent on the waveguide dimensions [12]. 


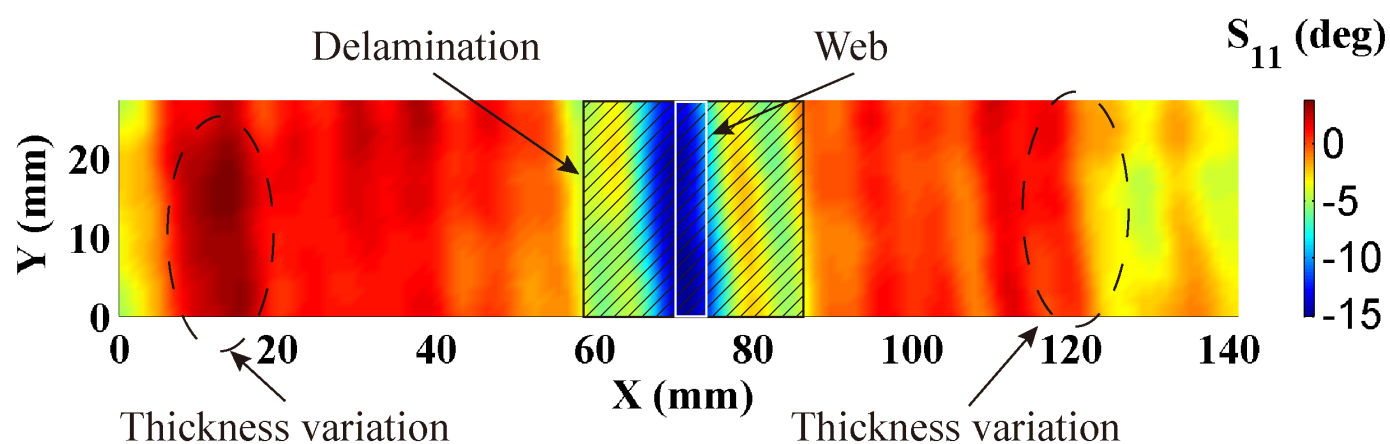

Fig.6: Microwave inspection of delamination in T-joint I at $19 \mathrm{GHz}$

As presented in Fig. 7, a similar result is found in T-joint II. The colour difference in the delamination region reveals the severity of the defects inside the joint. However, the same colour in different figures is not comparable, and the colour different indicating varied signal responses is only meaningful for a specific joint.

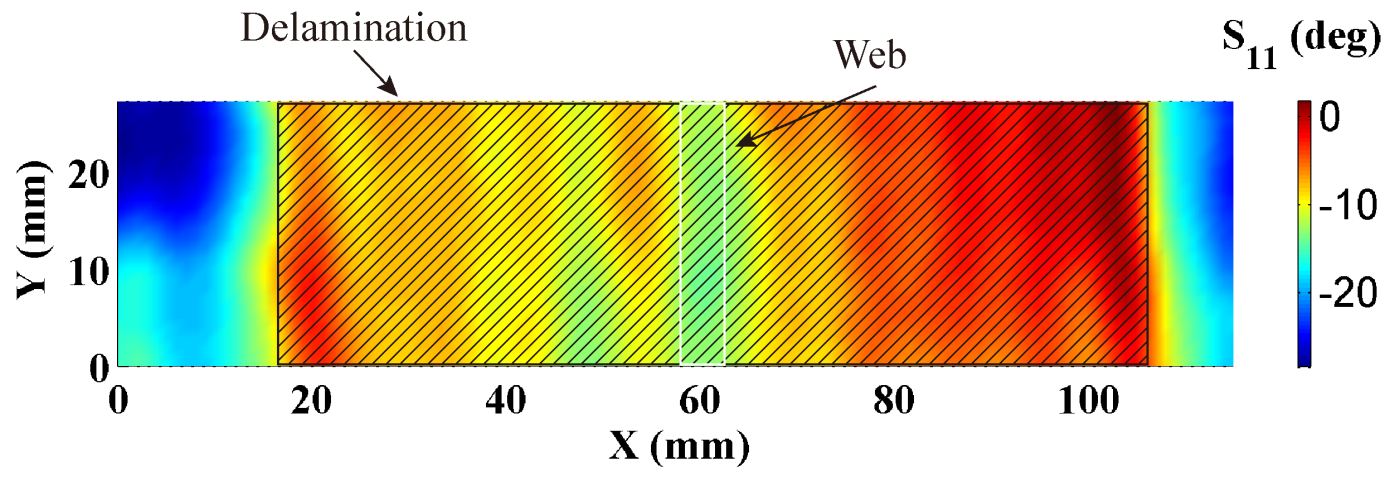

Fig.7: Microwave inspection of delamination in T-joint II at $19 \mathrm{GHz}$

\section{DISCUSSIONS}

(1) In order to study the effect of the inspection frequency on the signal response for the T-joint I case, four other inspection frequencies (i.e., $18 \mathrm{GHz}, 18.5 \mathrm{GHz}, 19.5 \mathrm{GHz}$ and $20 \mathrm{GHz}$ ) are examined. In Fig. 8, there is no clear difference between the distribution for the frequencies below $19.5 \mathrm{GHz}$. At the frequency of $20 \mathrm{GHz}$, the size of the delaminated region is around $40 \%$ larger than that in the cases with smaller frequencies. The location of the web can still be identified, although two unexpected blue strips exist on each side. The inconsistency of the inspection results is primarily due to the selection of the inspection frequency. It was found that the optimal frequency for inspection can only be determined from a well-prepared calibration [13]. For the present case, the recommended frequency range for the delamination detection is 18-19.5 GHz. However, it is noted that the choice of the optimum frequency range can only be made case by case. 


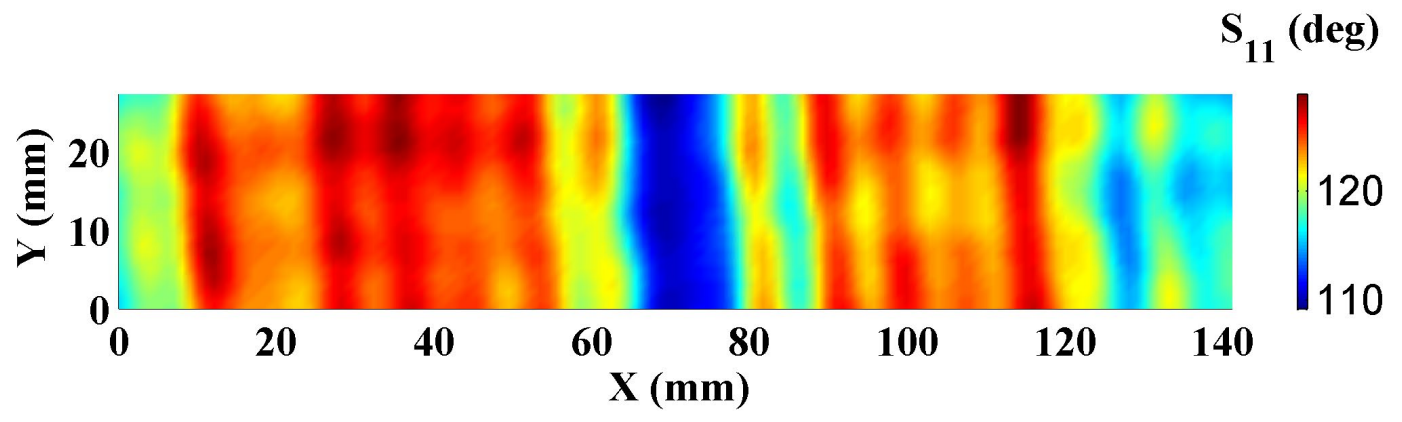

(a)

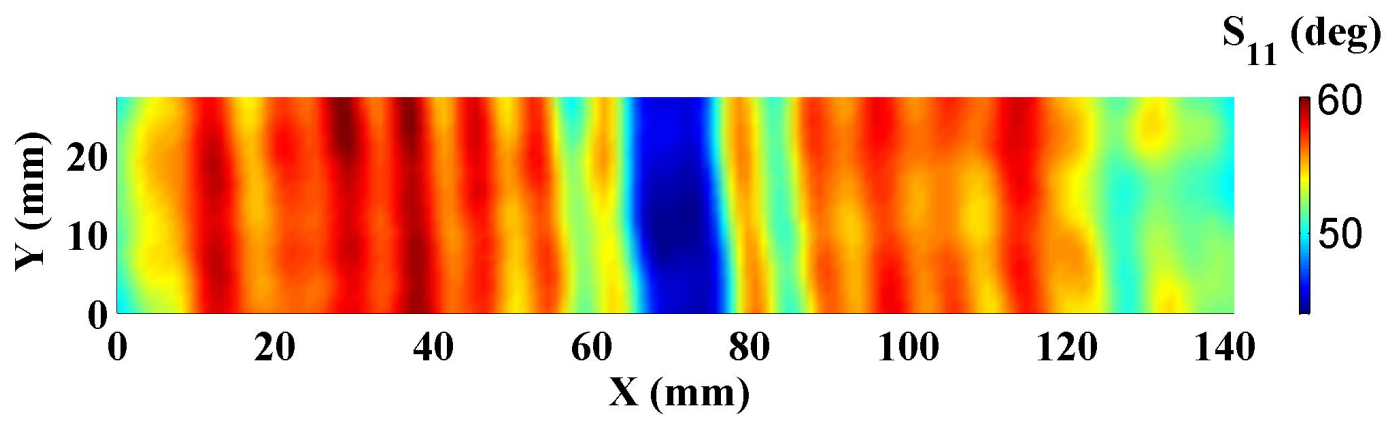

(b)

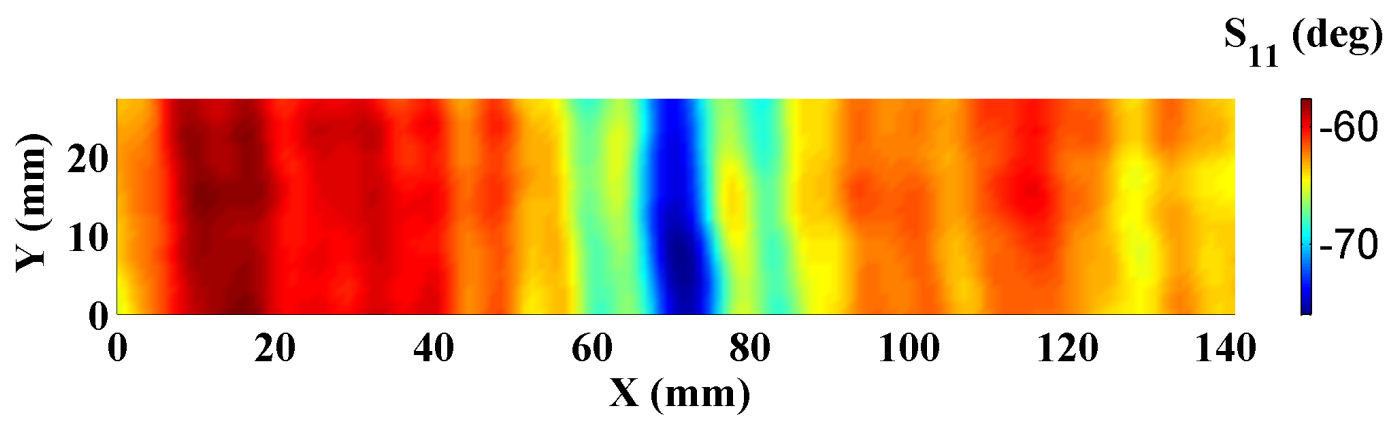

(c)

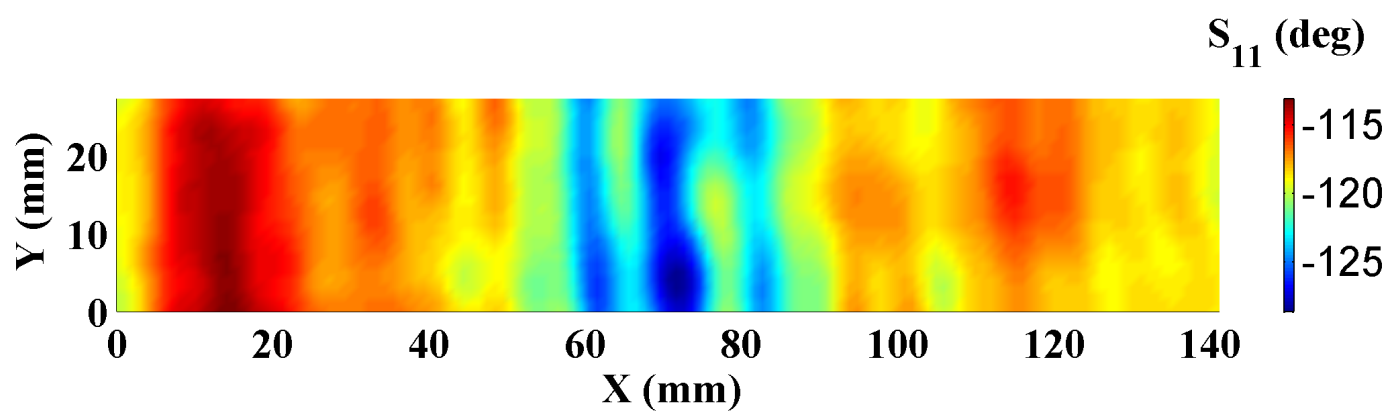

(d)

Fig.8: Inspection of T-joint I at varied frequencies:

(a) $18 \mathrm{GHz}$, (b) $18.5 \mathrm{GHz}$, (c) $19.5 \mathrm{GHz}$, (d) $20 \mathrm{GHz}$

(2) Here, the images of magnitude and phase for the delamination inspection are compared. As presented in Fig.9, the location of the web in T-joint I can be captured by the magnitude image at $18 \mathrm{GHz}$, but not the delamination, which can be explained by the little attenuation of the electromagnetic energy in its presence (air gaps). The electromagnetic wave could penetrate 
through the thickness, as the glass fibre composites are low-loss dielectric. Therefore, the magnitude is more sensitive to the variation of the thickness when compared with the phase information. In practice, the magnitude and phase information should be combined for damage evaluation.

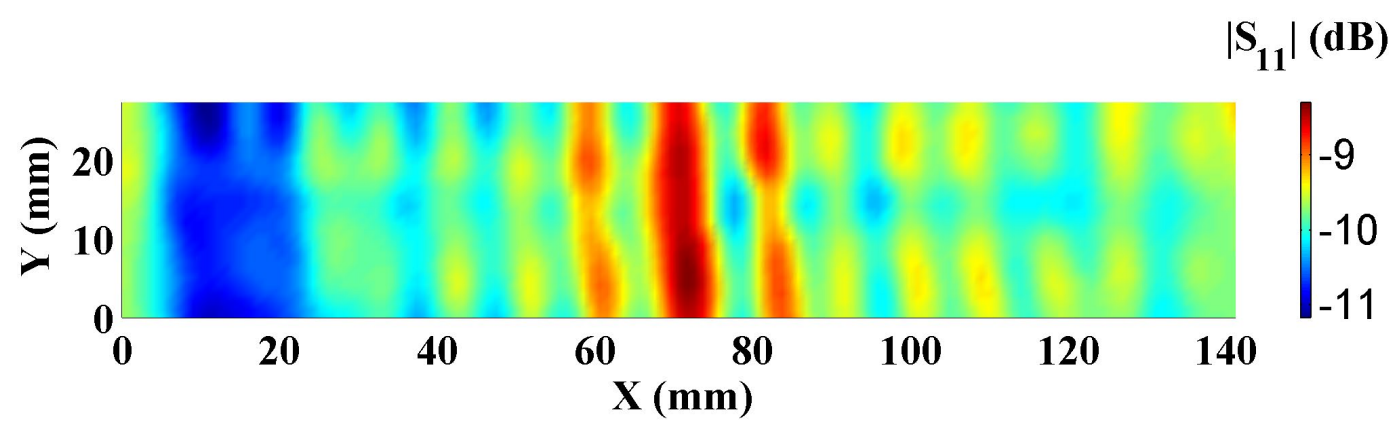

Fig.9: Microwave image of T-joint I represented by the magnitude profile distribution at $18 \mathrm{GHz}$

\section{CONCLUDING REMARKS}

The non-contact microwave imaging method has been successfully employed for the detection of the delamination in the glass fibre T-joints used in wind turbine blades. The regions of the delamination, variation of the thickness (due to flange tapering) and the presence of the web underneath the skin can be identified from the images obtained by the microwave scanning with an open-ended waveguide. The effect of the inspection frequency on the performance has been investigated. The optimum frequency range for the present case $(18-19.5 \mathrm{GHz})$ has been given based on the images produced at varied frequencies. Furthermore, by comparison, the phase of the reflection coefficient is better for the detection of the delamination, while the magnitude is more sensitive to the thickness variation. This microwave imaging technique shows promising results for further applications and development to the structural health monitoring of other wind turbine components.

For future work, the theoretical modelling of the open-ended rectangular waveguide radiating into a multi-layer dielectric structure can be introduced for better interpretation of the microwave images and identification of optimum inspection frequency range.

\section{ACKNOWLEDGEMENTS}

This work was funded by Dean's Doctoral Scholar Award, School of Materials, The University of Manchester. The first author gratefully acknowledges the support of Dr. Graham Parkinson from School of Electrical and Electronic Engineering for the assistance in the experiments. 


\section{References:}

1. Al-Khudairi, O. and Ghasemnejad, H., "To improve failure resistance in joint design of composite wind turbine blade materials", Renew. Energy, 81/(2015), 936-951.

2. Wymore, M. L., Van Dam, J. E., Ceylan, H. and Qiao, D., "A survey of health monitoring systems for wind turbines", Renew. Sustain. Energy Rev., 52/(2015), 976-990.

3. Brøndsted, P., Lilholt, H. and Lystrup, A., "Composite materials for wind power turbine blades", Annu. Rev. Mater. Res., 35/1(2005), 505-538.

4. Li, D., Ho, S.-C. M., Song, G., Ren, L. and Li, H., "A review of damage detection methods for wind turbine blades", Smart Mater. Struct., 24/3(2015), 033001.

5. Ciang, C. C., Lee, J.-R. and Bang, H.-J., "Structural health monitoring for a wind turbine system: a review of damage detection methods", Meas. Sci. Technol., 19/12(2008), 122001.

6. Kabir, M. J., Oo, A. M. T. and Rabbani, M., "A brief review on offshore wind turbine fault detection and recent development in condition monitoring based maintenance system", in 2015 Australasian Universities Power Engineering Conference (AUPEC), 2015, 1-7.

7. Carriveau, G. W., "Benchmarking of the state-of-the-art in nondestructive testing/evaluation for applicability in the composite armored vehicle (CAV) advanced technology demonstrator (ATD) program", San Antonio, (1993).

8. Kharkovsky, S. and Zoughi, R., "Microwave and millimeter wave nondestructive testing and evaluation - Overview and recent advances", IEEE Instrum. Meas. Mag., 10/2(2007), 26-38.

9. Wang, Y., Soutis, C., Hajdaei, A. and Hogg, P. J., "Finite element analysis of composite T-joints used in wind turbine blades", Plast. Rubber Compos., 44/3(2015), 87-97.

10. Qaddoumi, N., Ganchev, S. and Zoughi, R., "Microwave diagnosis of low-density fiberglass composites with resin binder", Res. Nondestruct. Eval., 8/3(1996), 177-188.

11. Hosoi, A. and Ju, Y., "Nondestructive detection of defects in GFRP laminates by microwaves", $J$. Solid Mech. Mater. Eng., 4/11(2010), 1711-1721.

12. Li, Z., Haigh, A., Soutis, C. and Gibson, A., "Simulation for the impact damage detection in composites by using the near-field microwave waveguide imaging", in The 53rd Annual Conference of The British Institute of Non-Destructive Testing, 2014.

13. Qaddoumi, N., Zoughi, R. and Carriveau, G. W., "Microwave detection and depth determination of disbonds in low-permittivity and low-loss thick sandwich composites", Res. Nondestruct. Eval., 8/1(1996), 51-63. 